\title{
Development of On-board Polytropic Index Prediction Model for Injection Timing Optimization of Diesel Engines
}

\author{
Mitsuhisa Ichiyanagi $^{1, \mathrm{a}}$, Hayao Joji2, ${ }^{2, \mathrm{~b}}$, Hiroki Matsui ${ }^{2, \mathrm{c}}$, Emir Yilmaz $^{2, \mathrm{~d}}$, Takashi Suzuki ${ }^{1, \mathrm{e}}$ \\ ${ }^{1}$ Department of Engineering and Applied Sciences, Sophia University, Tokyo, Japan \\ ${ }^{2}$ Graduate School of Science and Technology, Sophia University, Tokyo, Japan \\ aichiyanagi@sophia.ac.jp, bhayaojoji@eagle.sophia.ac.jp, ch-matsuideagle.sophia.ac.jp, \\ demiryilmaz@eagle.sophia.ac.jp, esuzu-tak@sophia.ac.jp
}

\begin{abstract}
Diesel engines are required to reduce exhaust emissions during real-world operations. In this regard, a new control concept called model-based control has been explored. Unlike the conventional method of relying on steady-state measurements, model-based control allows cycle-bycycle optimization of control inputs based on physical principles. Existing models for combustion control have been using empirical equations to predict polytropic index for the compression stroke for estimation of in-cylinder pressure and temperature at fuel injection. Therefore, in this study, a polytropic index prediction model was developed in MATLAB to maintain the engine performance under transient conditions and to reduce the required number of experiments. The model includes a heat loss model and a gas flow model to consider the effect of wall heat transfer and gas flows inside the cylinder. The computational load of the model was reduced through discretization of a single engine cycle into several calculation points. The model was validated against numerical simulation results under steady conditions first, and then applied to transient conditions for more realistic operational conditions. The model estimated the polytropic index with average errors under steady and transient conditions with $0.22 \%$ and $0.37 \%$, respectively. Finally, the calculation time of the model was evaluated to be $50.6 \mu \mathrm{s}$. It was concluded the model can be implemented on a model-based controller in the future.
\end{abstract}

Keywords: Model-based Control, Polytropic Index, Heat Loss.

\section{Introduction}

In recent years, Real Driving Emissions (RDE) has been introduced, and diesel engines are required to deliver low emissions not only under steady-state test bed conditions but also during real-world operations. Many previous studies have reported that steady-state engine behavior is significantly different from the actual behavior under transient conditions [1-3]. For example, one study [4] has shown that the cylinder wall temperature takes very long time (60-100 seconds, which corresponds to hundreds of engine cycles) to reach its thermal equilibrium. When the wall temperature is not in thermal equilibrium and $50 \mathrm{~K}$ higher than the steady-state wall temperature, the hotter walls advanced the fuel injection timing due to increased in-cylinder peak pressure and pressure rise rate [4]. In other words, non-equilibrium wall temperatures during transient operations vary the fuel injection timing and affect the thermal efficiency and pollutant formation [5]. Conventionally, fuel injection has been controlled by control maps, which are simple lookup tables developed from steady-state experiments. As expected, such maps have limitations when applied to transient conditions that is far from steady state [6]. On the other hand, a new control method called ModelBased Control (MBC) utilizes on-board models based on physical principles for real-time optimization of control inputs at each engine cycle. The on-board models are fast calculating control-oriented models, and its requirement is to finish calculations faster than a single engine cycle [7]. Not only MBC can shorten the development process for control maps and empirical equations because experiments are optional, it can maintain the engine performance under transient conditions.

Numerous on-board models [8-12] have been proposed, including a few models regarding combustion control [13-14]. In the combustion model for diesel engines with multiple fuel injections developed by Yamasaki et al. [14], a single engine cycle was discretized into several calculation points in an effort to reduce computational load. In-cylinder pressure and temperature were estimated at each discrete point based on theoretical equations. For estimation of the pressure and temperature at pilot- and pre-injection timings, the compression stroke from intake valve closing timing (IVC) to pilot- and pre-injection timings was assumed to undergo a polytropic process. In a polytropic process, thermodynamic properties such as pressure and temperature change in correspondence with a polytropic index which is a representation of specific heat ratio during a quasi-steady process including heat transfer. In internal combustion engines, heat transfer from combustion gases through the cylinder wall to the coolant is called heat loss. The existing combustion 
models employed empirical equations based on steadystate measurements for the estimation of polytropic index [13-14]. Thus, an on-board polytropic index prediction model based on physical principles has been demanded.

Heat transfer in internal combustion engines has been modeled extensively [15-19]. In recent years, some studies [20-21] proposed a theoretical model that considers spray-wall interactions while other study [22] developed a non-equilibrium model and compared it with existing models. Rakopoulos et al. [23] had successfully modeled heat transfer under transient operation without considering calculation speed. However, for MBC applications, they lack either robustness for a wide range of operational conditions or sufficient computational load. The authors had previously developed a theoretical heat loss model [24] based on the continuity equation and the law of conservation of energy, considering formulation of boundary layers inside the combustion chamber, while keeping the computational load low. To further improve the estimation accuracy, our previous study [25] developed a model for the gas flows inside the combustion chamber. The gas flow model determines flow velocities and turbulence intensities in the gas flows due to strong correlations between turbulence and heat transfer has been found [26].

The objective of this study is to develop an on-board polytropic index prediction model for the compression stroke of diesel engines that is reliable under transient driving conditions. The in-house developed model, written in a code of MATLAB, employs the heat loss model and the gas flow model that the authors have developed previously along with simple thermodynamic equations. In effort to reduce the computational load, calculation points are discretized to represent each engine cycle. The performance of the model is then evaluated compared to numerical simulation results under steady conditions. At last, compared to commercial 1-D engine simulation, the predictive ability of the model under transient conditions is explored. In addition, the calculation speed of the model is investigated for its possibility to be implemented on a model-based controller in the future.

\section{Numerical Simulation}

\subsection{Numerical Simulation Setup}

Commercially available CFD simulation and 1-D engine simulation software (refer as 1-D simulation hereon) called GT-Power were parameterized to match with experimental data. These tools are used to compare and evaluate the performance of the developed model under steady and transient conditions in following sections. CFD was validated in the previous study [25] while the 1-D simulation is validated in this paper. Engine specifications are shown in Table 1. Steady driving conditions are given in Table 2. Case 1 and 2 are high-load conditions with different engine speeds,
Case 3 is a mid-load condition, and Case 4 is a low-load condition with a high exhaust gas recirculation (EGR) rate. Transient driving conditions were generated based on the engine speed and indicated mean effective pressure (IMEP) of the steady conditions. For example, the time evolutions of engine speed, EGR rate, and mass of main injection are shown in Figure 1. The conditions can be divided into acceleration periods, constant-speed periods, and deceleration periods. The constant-speed periods are highlighted in Figure 1.

Table 1. Engine specifications

\begin{tabular}{ll}
\hline Bore [mm] & 85 \\
Stroke [mm] & 96.9 \\
Connection rod length [mm] & 150.5 \\
Compression ratio [-] & 16.3 \\
Intake valve opening duration [deg.] & -253 \\
Exhaust valve closing duration [deg.] & -268 \\
Number of injection nozzle holes [-] & 7 \\
Injection nozzle diameter [mm] & 0.12 \\
\hline
\end{tabular}

Table 2. Steady driving conditions

\begin{tabular}{lcccc}
\hline & Case 1 & Case 2 & Case 3 & Case 4 \\
\hline Engine speed [rpm] & 2250 & 2000 & 2000 & 1500 \\
IMEP [kPa] & 1442 & 1223 & 703 & 390 \\
Air-fuel ratio [-] & 22.4 & 20.1 & 22.4 & 27 \\
Intake air mass flow rate [g/s] & 67.5 & 47.1 & 30.2 & 15.5 \\
EGR rate [\%] & 10 & 18.2 & 29.2 & 42.9 \\
Intake air temp. [K] & 329 & 332.6 & 342.3 & 341.6 \\
Exhaust gas temp. [K] & 825.5 & 822.4 & 701.1 & 565.8 \\
Injection pres. [MPa] & 159.8 & 155.0 & 134.2 & 90.7 \\
\hline
\end{tabular}

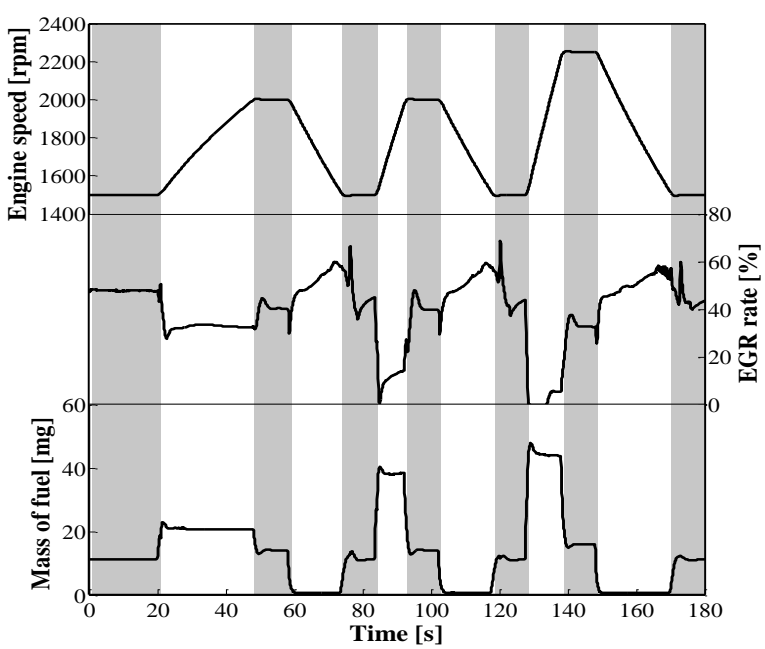

Figure 1. Evolution of transient driving conditions: engine speed, EGR rate, and mass of fuel injected

\subsection{Validation of 1-D Simulation}

The 1-D simulation is validated against experimental results. Table 3 is a summary of comparison between the IMEP obtained from experiment and the 1-D simulation under the steady driving conditions. The average error across the conditions was $1.7 \%$, while the maximum error was $2.8 \%$ for Case 4 . For low-load conditions with a high EGR rate as in Case 4, the estimation accuracy needs to be reevaluated in the future. 
Table 3. Comparison of experimental and 1-D simulation IMEP under steady conditions

\begin{tabular}{lcccc}
\hline & Case 1 & Case 2 & Case 3 & Case 4 \\
\hline Experiment [kPa] & 1441.6 & 1222.7 & 703.3 & 390.1 \\
1-D simulation [kPa] & 1423.4 & 1231.3 & 688.8 & 400.8 \\
Error ratio [\%] & 1.3 & 0.7 & 2.1 & 2.8 \\
\hline
\end{tabular}

\section{Polytropic Index Prediciton Model}

\subsection{Model Outline}

The required inputs of the model are engine speed, $\mathrm{A} / \mathrm{F}$ ratio, EGR rate, boost pressure, exhaust pressure, intake air temperature, exhaust gas temperature, coolant temperature, oil temperature, mass and timings of pilot, pre, and main injections. The inputs include the timings and quantities of pilot and pre fuel injections to be applicable for diesel engines with multiple fuel injections. The output of this model is the polytropic index for the compression stroke. The model follows the flowchart shown in Figure 2 at each cycle starting from the inputs. First, the model estimates the incylinder gas pressure and temperature based on simple thermodynamic equations [27]. The gas composition is estimated by the gas composition model [28] to calculate the specific heat values. Then, with the gas flow model [25], the heat loss is estimated. The average wall surface temperature inside the combustion chamber (refer as wall temperature) is obtained, and lastly, the polytropic index is predicted. The calculation details of each stage in Figure 2 are described in Section 3.3.

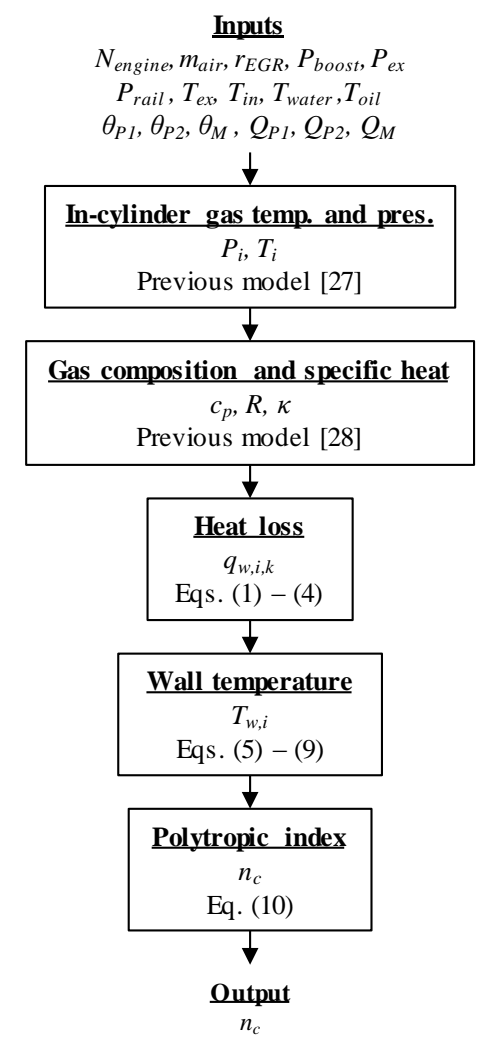

Figure 2. The calculation flow of the model

\subsection{Reduction of Computational Load}

Table 4 is a list of 22 discrete points and corresponding crank angles (CA). In Figure 3, the dotted line represents the in-cylinder pressure of a typical diesel engine while the dots represent corresponding discrete points. The discrete points represent the specific points of a common diesel cycle such as intake valve opening and closing timings (IVO and IVC) as well as exhaust valve opening and closing timings (EVO and EVC). Other points are selected to maintain the calculation accuracy of the gas flow model [25] while to minimize the computational load for onboard applications. From this section, each discrete point is referred as "point".

Table 4. Discrete points

\begin{tabular}{ccccccc}
\hline Point & 1 & 2 & 3 & 4 & 5 & 6 \\
CA & 0 & EVC & 45 & 60 & 75 & 90 \\
\hline Point & 7 & 8 & 9 & 10 & 11 & 12 \\
CA & 135 & 180 & IVC & 270 & 300 & 320 \\
\hline Point & 13 & 14 & 15 & 16 & 17 & 18 \\
CA & 340 & TDC & 369 & 374 & 380 & 395 \\
\hline Point & 19 & 20 & 21 & 22 & & \\
CA & 405 & EVO & 600 & IVO & & \\
\hline
\end{tabular}

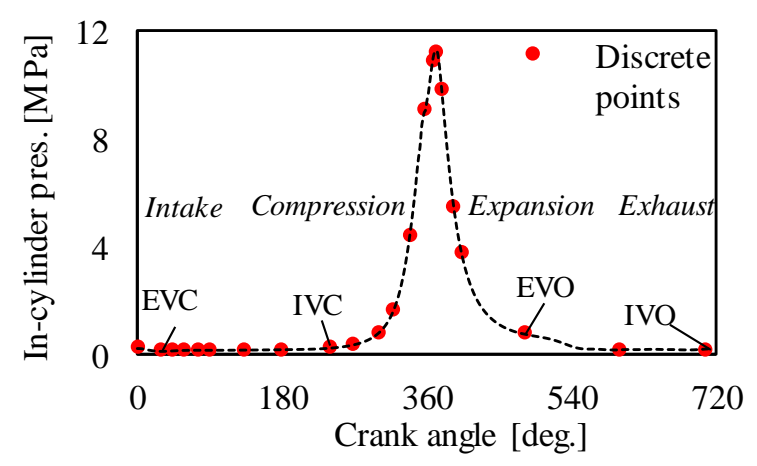

Figure 3. In-cylinder pressure of a typical diesel cycle and outline of the discrete points

\subsection{Detailed Model Description}

\subsubsection{Heat Loss}

Heat loss, or the total amount of heat transfer from combustion gases through the cylinder wall to the coolant, heavily depends on the gas flows inside the cylinder as well as the turbulence in the gas flow [26]. To reduce the computational load of the model, the model does not calculate the turbulence. Instead, the turbulence intensity is estimated from gas flow velocities calculated by the developed gas flow model and turbulence intensity coefficients obtained by CFD [25]. Since various gas flows cause turbulence at different parts of the cylinder, the heat transfer is not uniform to the wall. Therefore, the cylinder was divided into six regions as shown in Figure 4 considering the effects of the gas flows, modeled in our successive work [25]. The total heat flux is written as the sum of heat flux by conduction and convection [24]. 


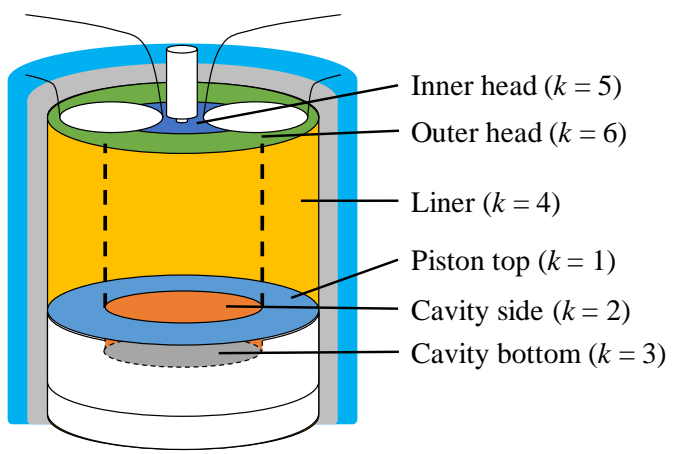

Figure 4. Cylinder regions

$$
\begin{aligned}
q_{w, i, k}=-\left(q_{w c d}+q_{w c v}\right) & =-\sqrt{\frac{C_{\lambda}}{P_{0}} \frac{\kappa}{\kappa-1}} P_{i} T_{i}\left\{\frac{1}{\sqrt{\pi \tau}}-\frac{T_{w, k}}{T_{i}} \frac{1}{\sqrt{\tau}}\right\}-\frac{\psi}{4} c_{p} \hat{u}_{i, k}^{\prime} \frac{P_{i}}{P_{0}}\left(T_{i}-T_{w, k}\right) \\
\tau & =\frac{1}{P_{0}} \int_{0}^{t} P d t
\end{aligned}
$$

Here $q_{w, i, k}$ is the heat flux from the gas to the cylinder wall of region $k$ at discretized point $i\left[\mathrm{~W} / \mathrm{m}^{2}\right]$, $q_{w c d}$ is the heat flux by conduction $\left[\mathrm{W} / \mathrm{m}^{2}\right], q_{w c v}$ is the heat flux by convection $\left[\mathrm{W} / \mathrm{m}^{2}\right], C_{\lambda}$ is the ratio of thermal conductivity to gas temperature $\left[\mathrm{W} /\left(\mathrm{m} \cdot \mathrm{K}^{2}\right)\right], P_{0}$ is the in-cylinder pressure at TDC during the intake stroke (point 1) $[\mathrm{Pa}], \kappa$ is the specific heat ratio $[-], P_{i}$ is the in-cylinder pressure at point $i[\mathrm{~Pa}], T_{i}$ is the gas temperature at point $i[\mathrm{~K}], \tau$ is dimensionless time $[-]$, $T_{w, k}$ is the wall temperature of region $k$ in the previous cycle $[\mathrm{K}], \psi(=0.4)$ is the Karman constant $[-], c_{p}$ is the specific heat capacity at constant pressure $[\mathrm{J} /(\mathrm{kg} \cdot \mathrm{K})]$, $\hat{u}_{i, k}^{\prime}$ is the turbulence intensity of region $k$ at point $i$ $[\mathrm{m} / \mathrm{s}]$ [25], and $t$ is the elapsed time from TDC during the intake stroke (point 1) [s].

The rate of heat transfer from combustion gases to the in-cylinder wall surface can be obtained by multiplying the heat flux by the area of each region. Lastly, the heat loss is estimated by Eq. (4).

$$
\begin{gathered}
\dot{Q}_{w, i, k}=q_{w, i, k} A_{k} \\
Q_{w, c y c l e}=\dot{Q}_{w, i, k} \Delta t_{\text {cycle }}
\end{gathered}
$$

where $\dot{Q}_{w, i, k}$ is the rate of heat transfer from the gas to the wall [W], $A_{k}$ is the surface area of region $k[\mathrm{~K}]$, $Q_{w, \text { cycle }}$ is the heat loss of a cycle [J], and $\Delta t_{\text {cycle }}$ is the elapsed time [s].

\subsubsection{Wall Temperature}

Assuming a quasi-steady process, the rate of heat transfer from the gas to the in-cylinder wall surface is equivalent to the rate of heat released from the incylinder wall surface to the surrounding coolant.

$$
\dot{Q}_{w, \text { cycle }}=\dot{Q}_{\text {coolant }}
$$

Here $\dot{Q}_{\text {coolant }}$ is the amount of heat released from the wall to the coolant [W]. At cylinder regions $k=1,2$,
4, 5, and 6, the wall temperatures are obtained by Newton's law of cooling.

$$
T_{w, k}=T_{\text {coolant }}+\dot{Q}_{w, \text { cycle }} \frac{1}{A_{k} K_{k}}
$$

Here $T_{\text {coolant }}$ is the temperature of coolant $[\mathrm{K}]$, and $K_{k}$ is the overall heat transfer coefficient of region $k$ $\left[\mathrm{W} /\left(\mathrm{m}^{2} \cdot \mathrm{K}\right)\right]$. The cylinder liner is made of iron while other regions are made of aluminum. The overall heat transfer coefficient of each area is estimated based on thermal conductivity and the Dittus-Boelter equation [29] for the coolant side.

At the cavity bottom $(k=3)$, unlike other regions, heat is transferred from the wall to both coolant and lubricating oil. Assuming the heat released from the wall is distributed to the coolant by $\alpha$, it is released to the lubricating oil by $1-\alpha$. The wall surface temperature at region $k=3$ can be written as

$$
\begin{gathered}
T_{w, 3}=T_{\text {coolant }}+\dot{Q}_{w, \text { cycle }} \frac{\alpha}{A_{3} K_{\text {coolant }}} \\
T_{w, 3}=T_{\text {oil }}+\dot{Q}_{w, \text { cycle }} \frac{(1-\alpha)}{A_{3} K_{\text {oil }}}
\end{gathered}
$$

where $\alpha$ is the distribution ratio of heat transfer from the cavity bottom [-], $K_{\text {coolant }}$ is the overall heat transfer coefficient of coolant at region $k=3\left[\mathrm{~W} /\left(\mathrm{m}^{2} \cdot \mathrm{K}\right)\right], T_{\text {oil }}$ is the temperature of lubricating oil [K], $K_{\text {oil }}$ is the overall heat transfer coefficient of lubricating oil at region $k=3$ $\left[\mathrm{W} /\left(\mathrm{m}^{2} \cdot \mathrm{K}\right)\right]$. Rewriting Eqs. (7) and (8), the wall temperature at the cavity bottom can be given with the following equation.

$$
T_{w, 3}=\frac{\left(\dot{Q}_{w, \text { cycle }} / A_{3}\right)+T_{\text {coolant }} K_{\text {coolant }}+T_{\text {oil }} K_{\text {oil }}}{K_{\text {coolant }}+K_{\text {oil }}}
$$

\subsubsection{Polytropic Index for Compressions Stroke}

The polytropic index is predicted by the following equation, which was derived based on the first law of thermodynamics and the polytropic process equation.

$$
Q_{I V C-\theta}=\int_{I V C}^{\theta} \frac{\kappa-n_{c}}{\kappa-1} P d V=\frac{\kappa-n_{c}}{\kappa-1} \frac{P_{I V C} V_{I V C}}{n_{c}-1}\left\{1-\left(\frac{V_{I V C}}{V_{\theta}}\right)^{n_{c}-1}\right\}
$$

Here $Q_{I V C-\theta}$ is the heat loss from IVC to crank angle $\theta[\mathrm{J}], n_{c}$ is the polytropic index for the compression stroke predicted in the previous cycle [-], $P_{I V C}$ is the incylinder pressure at IVC $[\mathrm{Pa}], V_{I V C}$ is the cylinder volume at IVC $\left[\mathrm{m}^{3}\right]$, and $V_{\theta}$ is the cylinder volume at crank angle $\theta\left[\mathrm{m}^{3}\right]$. A statistical analysis is applied to the equation to isolate and determine the polytropic index.

\section{Results and Discussion}

\subsection{Validation of the Model under Steady Driving Conditions}




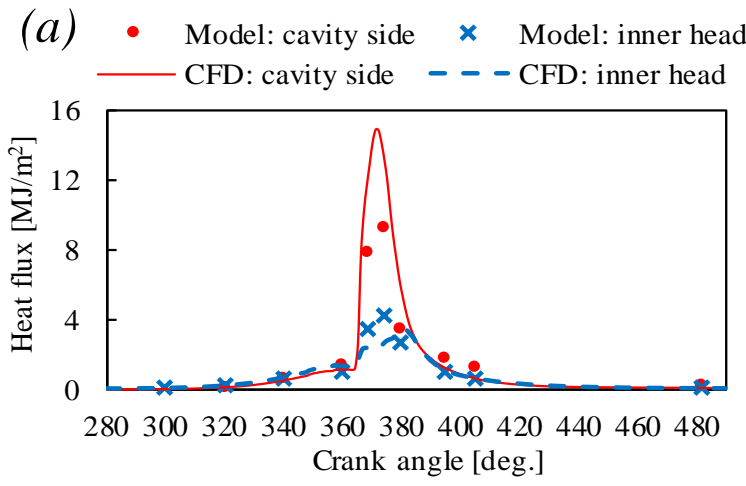

(b) - Model: cavity side $\times$ Model: inner head

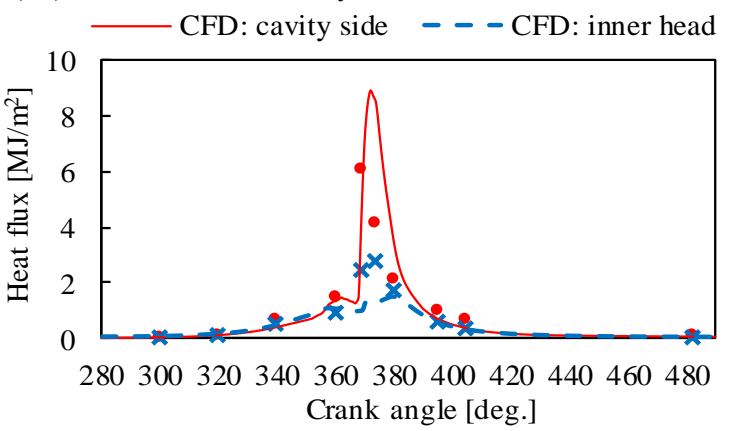

Figure 5. Comparison between the heat flux of the model and CFD at cavity side and inner heat for (a) Case 2 and $(b)$ Case 3

The developed model is validated through comparison with experimental and numerical simulation results. Under the steady driving conditions in Table 2, the IMEP calculated by the model is compared to experimental results. The average estimation error is $2.2 \%$ whereas the error between the experimental results and 1-D simulation is $1.7 \%$.

CFD results are chosen to validate the heat flux of each region because the 1-D simulation cannot estimate the heat flux at each cylinder region. For example, Figure 5 compares the heat flux at the cavity side and inner head ( $k=2$ and 5$)$ obtained by the model and CFD. Figure 5(a) and 5(b) correspond to Case 2 and Case 3, respectively. The heat flux at the piston rises sharply after fuel injection due to a diffusion flame directly colliding with the piston and falls shortly after the end of combustion. The CFD results show that the heat flux is largely different depending on cylinder regions and operating conditions. From both figures, it is evident that the model can reproduce the heat fluxes estimated by CFD reasonably well. Comparing two figures, the heat flux obtained for Case 2 is much larger than the ones for Case 3, illustrating the approximation capability of the model under different operating conditions. It can also be noted that during combustion, approximately $360^{\circ}-395^{\circ}$, the performance of the model noticeably deteriorates due to the fact that combustion is not considered in the developed model. Although the estimation error increases during combustion, IMEP estimation has been validated in the previous paragraph. The influence of the heat flux approximation error during combustion on the prediction accuracies of heat loss, wall temperature, and polytropic index is investigated in the next paragraphs.

The heat loss of each area is computed from the heat flux and added to obtain the total heat loss per cycle. In Figure 6, the total heat loss approximated by the model is compared with CFD results. Comparing the results, at the cylinder liner and head, the model estimates the heat loss accurately. However, at the piston, the estimation accuracy decreases slightly. This is attributed to the estimation error in heat flux at the piston during combustion, which was mentioned in the previous paragraph. It is also evident that as the engine load decreases from Case 1 to 4 , the total heat loss decreases as well.

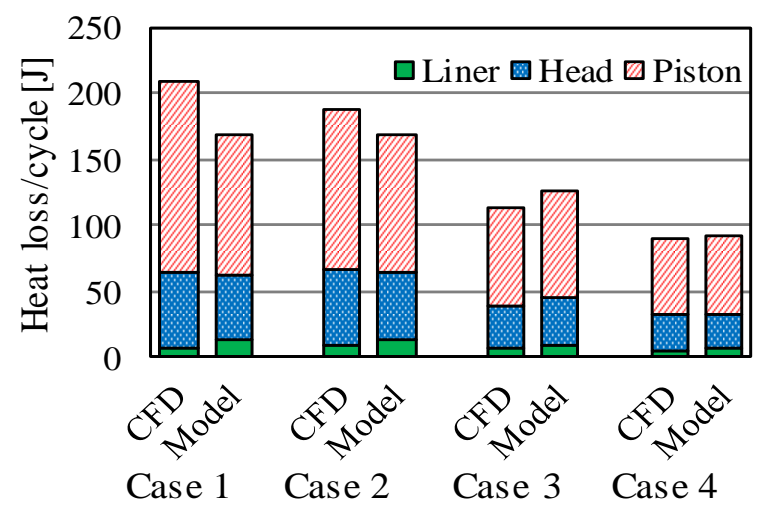

Figure 6. Summation of liner, head, and piston heat losses by model and CFD in each case

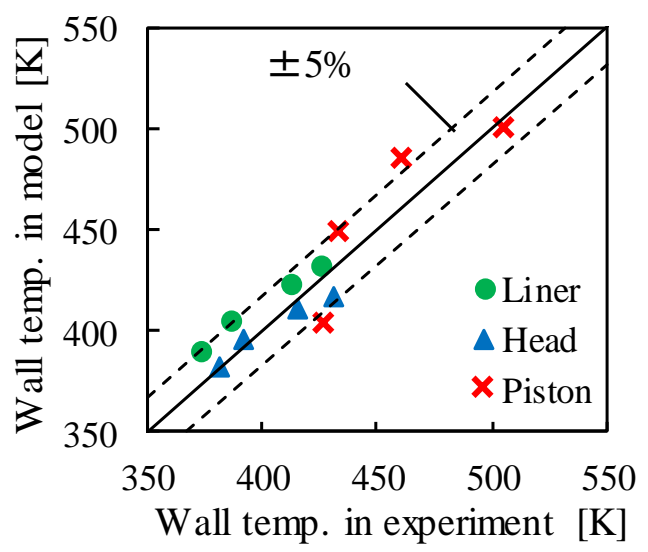

Figure 7. Comparison of wall temperatures at piston, liner, and head under the four cases of steady driving conditions

For the engine specified in Table 1, the wall temperatures of liner, head, and piston were measured under the steady conditions. Figure 7 compares the experimental results to the area averaged wall temperatures of piston, liner, and head under the steady driving conditions. The figure shows that the wall temperature at piston is generally higher than the ones at other regions due to the higher heat loss that can be seen in Figure 6. Additionally, as the engine load decreases from Case 1 to 4 , because the heat loss at each region decreases, the wall temperature decreases as well. The figure illustrates the high estimation accuracy of the model in wall temperatures despite the 
estimation error in heat flux during combustion. The average error is $2.8 \%$ while the maximum error is $5.6 \%$.

Table 5 presents the calculated heat loss during the compression stroke $\left(240^{\circ}-340^{\circ}\right)$ which directly influences the polytropic index. Unlike the heat loss of a single cycle, the heat loss during the compression stroke increases as the load decreases from Case 1 to 4 . This is because heat is a function of temperature difference between the gas and the wall. At the end of compression stroke, the gas temperature is fairly similar regardless of the load. On the other hand, the wall temperature is lower as the load decreases which was shown previously. The decrease in wall temperature means the temperature difference between the gas and the wall becomes greater, resulting in higher heat loss.

The polytropic indices for the compression stroke predicted by the model and 1-D simulation are compared in Table 5. The polytropic index decreases from Case 1 to Case 4 as the heat loss during compression stroke increases. This tendency represents the inverse relationship of polytropic index and heat loss which is shown in Eq. (10). The average prediction error of the model compared to 1-D engine simulation is $0.22 \%$ across the steady driving conditions. With the obtained polytropic index results, the in-cylinder gas temperature is estimated. Based on the assumption that the fuel is injected into the chamber as soon as the gas temperature reaches $850 \mathrm{~K}$, the prediction error of fuel injection timing was evaluated in Table 5. It is evident that the polytropic index predicted by the model is capable of estimating the injection timing within the accuracy of 1.0 degree under steady driving conditions. In the next section, the model is evaluated under transient driving conditions for its possibility of realworld application.

Table 5. Discrete points

\begin{tabular}{lcccc}
\hline & Case 1 & Case 2 & Case 3 & Case 4 \\
\hline Heat loss during comp. stroke [J] & 8.097 & 8.447 & 9.413 & 10.019 \\
\hline$n_{c}$ [-]: model & 1.376 & 1.370 & 1.359 & 1.351 \\
$n_{c}$ [-]: 1-D sim. & 1.372 & 1.365 & 1.356 & 1.351 \\
$n_{c}$ error [\%] & $0.29 \%$ & $0.38 \%$ & $0.19 \%$ & $0.02 \%$ \\
\hline Inj. Timing [deg.]: model & 337.61 & 337.78 & 340.09 & 342.70 \\
Inj. Timing [deg.]: model & 338.20 & 338.55 & 340.09 & 342.70 \\
Difference in inj. timing [deg.] & 0.59 & 0.77 & 0.42 & 0.06 \\
\hline
\end{tabular}

\subsection{Validation of the Model under Transient Driving Conditions}

The developed model is also validated under transient driving conditions by comparing it to the 1-D simulation and experimental results. The wall temperatures based on the experimental data are compared to the model for validation. The comparison at the cylinder head ( $k=5$ and 6$)$ is shown in Figure 8. The wall temperature increases during high-load operation such as during acceleration, as expected. As shown in the figure, the model exhibits a similar characteristic across various operating conditions compared to the experimental results. The area average wall temperature for all regions is also taken and compared. The average errors in wall temperature estimation when the engine speed is constant and during acceleration are $1.94 \%$ and $4.58 \%$, respectively. Although the performance deteriorates slightly during acceleration, the model is capable of estimating the wall temperature accurately under transient driving conditions.

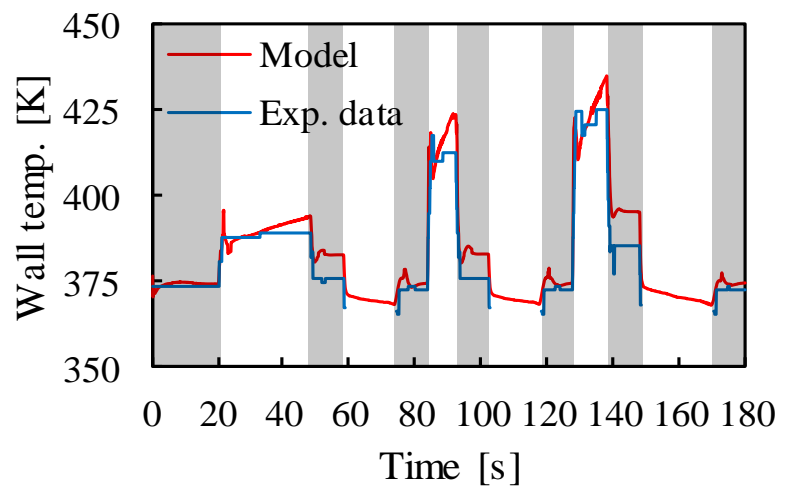

Figure 8. Comparison of wall temperatures at piston, liner, and head under the four cases of steady driving conditions

At last, the polytropic index predicted by the model under the transient driving conditions is compared to 1-D simulation results in Figure 9. The model achieved accurate prediction with an average error of $0.37 \%$. Although the model maintains its estimation accuracy at $0.75 \%$ during deceleration, the trend of the model does not follow that of 1-D simulation. This is due to the fact that the mass of main fuel injection during deceleration is nearly zero which is shown in Figure 1. Since the model is developed based on the steady driving conditions in Table 2, its performance deteriorates slightly for such particular cases. However, when the mass of fuel injection is nearly zero, the polytropic index is insignificant as its purpose is to predict the optimal fuel injection timing. Therefore, the increase in estimation error during deceleration is negligible. The high prediction accuracies of wall temperature as well as polytropic index for the compression stroke are verified with the results.

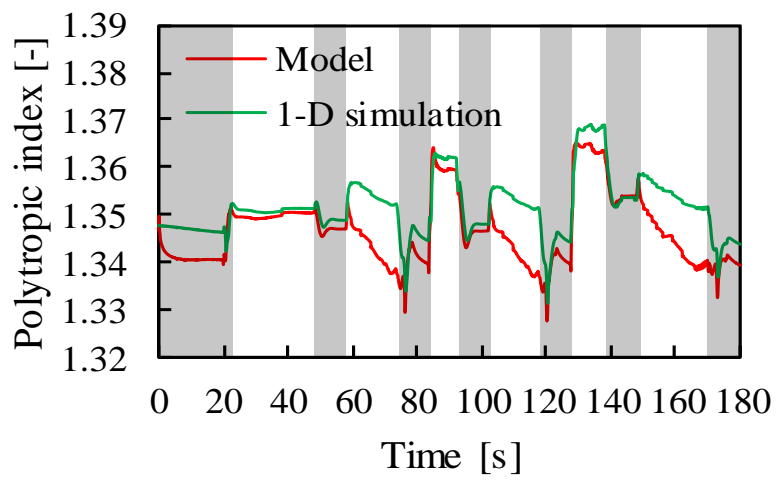

Figure 9. Time evolution of polytropic index for compression stroke predicted by the model and 1-D simulation 


\subsection{Evaluation of the Computational Load}

The computational load of the model is evaluated to verify the applicability of the model for model-based control. Calculations were performed on a typical personal computer (OS: Windows10 Home 64bit, CPU: Intel Core i5-4200U@1.6GHz, Memory: 4GB). The calculation time for a cycle was approximately $50.6 \mu \mathrm{s}$. By contrast, one engine cycle at an engine speed of $2250 \mathrm{rpm}$ takes about $53.3 \mathrm{~ms}$. Although a typical ECU runs slower than the PC used for evaluation, it is apparent that the calculation time of the model is faster than the time of a single engine cycle. The model is capable of being implemented in a feed-forward controller for real-time prediction of polytropic index.

\section{Conclusions}

A polytropic index prediction model for the compressions stroke of diesel engines was developed in MATLAB. The developed model has a low computational load, and it predicts the polytropic index based on physical principles from operational conditions in each cycle. The model was validated under steady-state conditions first. Then, it was applied to transient driving conditions to explore the possibility for real-world applications. Based on the studies presented, the following conclusions were obtained:

1. Under the steady driving conditions, the model predicted the polytropic index for the compression stroke with an average error of $0.22 \%$ compared to the 1-D simulation. With the estimation accuracy, the model is expected to estimate the fuel injection timing within an error range of $0.5^{\circ}$.

2. Under the transient driving conditions, the model predicted the polytropic index with an average error of $0.37 \%$. Although the error increased slightly during deceleration where the mass of fuel injection is nearly zero, it is considered negligible as the polytropic index is insignificant when there is no fuel injection.

3. The calculation time of the model was $50.6 \mu$ s per cycle. It is significantly faster than a single engine cycle; thus, the model can be implemented on engine system controllers.

\section{Acknowledgement}

The authors disclosed receipt of the following financial support for the research, authorship, and/or publication of this article: This work was supported by the Council for Science, Technology, and Innovation (CSTI), Cross-ministerial Strategic Innovation Promotion Program (SIP), "Innovative Combustion Technology" (funding agency: JST) and Japan Society for the Promotion of Science, Grants-in-Aid for Scientific Research (No.16K06129).

\section{References}

1. Erison, C., Westerberg, B., and Egnell, R., Transient Emission Predictions with Quasi Stationary Models, SAE Powertrain \& Fluid Systems Conference \& Exhibition, San Antonio (TX, USA), Oct. 2005, SAE Technical Paper 2005-01-3852, doi: 10.4271/ 2005-01-3852.

2. Rakopoulos, C.D. and Giakoumis, E.G., Review of Thermodynamic Diesel Engine Simulations under Transient Operating Conditions, SAE 2006 World Congress \& Exhibition, Detroit (MI, USA), Apr. 2006, SAE Technical Paper 2006-01-0884, doi: 10.4271/2006-01-0884.

3. Assanis, D.N., Filipi, Z.S., Fiveland, S.B., and Syrimis, M., A Predictive Ignition Delay Correlation under Steady-State and Transient Operation of a Direct Injection Diesel Engine, Journal of Engineering for Gas Turbines and Power, 125(2), Apr. 2003, pp. 450-457, doi: 10.1115/1.1563238.

4. Chang, K., Lavoie, G.A., Babajimopoulos, A., Filipi, Z.S., and Assanis, D.N., Control of a MultiCylinder HCCI Engine During Transient Operation by Modulating Residual Gas Fraction to Compensate for Wall Temperature Effects, $S A E$ 2007 World Congress \& Exhibition, Detroit (MI, USA), Apr. 2007, SAE Technical Paper 2007-010204, doi: 10.4271/2007-01-0204.

5. Hillion, M., Buhlbuck, H., Chauvin, J., and Petit, N., Combustion Control of Diesel Engines Using Injection Timing, SAE 2009 World Congress \& Exhibition, Detroit (MI, USA), Apr. 2009, SAE Technical Paper 2009-01-0367, doi: 10.4271/200901-0367.

6. Gao, Z., Conklin, J.C., Daw, C.S., and Chakravarthy, V.K., A Proposed Methodology for Estimating Transient Engine-out Temperature and Emissions from Steady-state Maps, International Journal of Engine Research, 11(2), Apr. 2010, pp. 137-151, doi: 10.1243/14680874JER05609.

7. Yasuda, K., Yamasaki, Y., Kaneko, S., Nakamura, Y., Iida, N., and Hasegawa, R., Diesel Combustion Model for On-board Application, International Journal of Engine Research, 17(7), Sep. 2016, pp. 748-765, doi: 10.1177/1468087415611331.

8. Kocher, L., Koeberlein, E., Stricker, K., Van Alstine, D.G., Biller, B., and Shaver, G.M., Controloriented Modeling of Diesel Engine Gas Exchange, Proc. of the 2011 American Control Conference, San Francisco (CA, USA), Jun. 2011, Paper No. 12270120, doi: 10.1109/ACC.2011.5991425.

9. Xie, H., Li, S., Song, K., and He, G., Model-based Decoupling Control of VGT and EGR with Active Disturbance Rejection in Diesel Engines, IFAC Proceedings Volumes, 46(21), 2013, pp. 282-288, doi: 10.3182/20130904-4-JP-2042.00149.

10. Reß, J., Stürzebecher, C., Bohn, C., Märzke, F., and Frase, R., A Diesel Engine Model Including Exhaust Flap, Intake Throttle, LP-EGR and VGT - 
Part I: System Modeling, IFAC-PapersOnLine, 48(15), 2015, pp. 52-59, doi: 10.1016/j.ifacol.2015. 10.008 .

11. Ma, J., Xu, F., Huang, K., and Huang, R., Improvement on the Linear and Nonlinear AutoRegressive Model for Predicting the NOx Emission of Diesel Engine, Neurocomputing, 207, Sep. 2016, pp. 150-164, doi: 10.1016/j.neucom.2016.03.075.

12. Dickinson, P., Glover, K., Collings, N., Yamashita, Y., Yashiro, Y., and Hoshi, T., Real-Time Control of a Two-Stage Serial VGT Diesel Engine Using MPC, IFAC-PapersOnLine, 48(15), 2015, pp. 117123, doi: 10.1016/j.ifacol.2015.10.017.

13. Ravi, N., Roelle, M.J., Liao, H., Jungkunz, A.F., Chang, C., Park, S., and Gerdes, J.C., Model-based Control of HCCI Engines Using Exhaust Recompression, IEEE Transactions on Control Systems Technology, 18(6), Nov. 2010, pp. 12891302, doi: 10.1109/TCST.2009.2036599.

14. Yamasaki, Y., Ikemura, R., and Kaneko, S., Modelbased Control of Diesel Engines with Multiple Fuel Injections, International Journal of Engine Research, 19(2), Feb. 2018, pp. 257-265, doi: $10.1177 / 1468087417747738$.

15. Soyhan, H.S., Yasar, H., Walmsley, H., Head, B., Kalghatgi, G.T., and Sorusbay, C., Evaluation of Heat Transfer Correlations for HCCI Engine Modeling, Applied Thermal Engineering, 29(2-3), Feb. 2009, pp. 541-549, doi: 10.1016/ j.applthermaleng.2008.03.014.

16. Chang, J., Güralp, O., Filipi, Z., Assanis, D., Kuo, T., Najt, P., and Rask, R., New Heat Transfer Correlation for an HCCI Engine Derived from Measurements of Instantaneous Surface Heat Flux, SAE 2004 Powertrain \& Fluid Systems Conference \& Exhibition, Tampa (FL, USA), Oct. 2004, SAE Technical Paper 2004-01-2996, doi: 10.4271/200401-2996.

17. Descieux, D. and Feidt, M., One Zone Thermodynamic Model Simulation of an Ignition Compression Engine, Applied Thermal Engineering, 27(8-9), Jun. 2007, pp. 1457-1466, doi: 10.1016/ j.applthermaleng.2006.10.002.

18. Hohenberg, G.F., Advanced Approaches for Heat Transfer Calculations, 1979 SAE International OffHighway and Powerplant Congress \& Exposition, Milwaukee (WI, USA), Sep. 1979, SAE Technical Paper 790825, doi: 10.4271/790825.

19. Schubert, C., Wimmer, A., and Chmela, F., Advanced Heat Transfer Model for CI Engines, $S A E$ 2005 World Congress \& Exhibition, Detroit (MI, USA), Apr. 2005, SAE Technical Paper 2005-010695, doi: 10.4271/2005-01-0695.

20. Inagaki, K., Mizuta, J., Nomura, Y., Ikedo, T., and Ueda, R., Proposal of Wall Heat Transfer Coefficient Applicable to Spray-Wall Interaction Process in Diesel Engines (First Report), 2018 JSAE
Annual Congress Spring, Yokohama (Japan), May 2018.

21. Fujikawa, S., Nakata, M., Maeda, S., Arai, N., Matsumura, E., Senda, J., and Inagaki, K., Proposal of Wall Heat Transfer Coefficient Applicable to Spray-Wall Interaction Process in Diesel Engines (Second Report), 2018 JSAE Annual Congress Spring, Yokohama (Japan), May 2018.

22. Ma, P.C., Greene, M., Sick, V., and Ihme, M., NonEquilibrium Wall-Modeling for Internal Combustion Engine Simulations with Wall Heat Transfer, International Journal of Engine Research, 18(1-2), Feb. 2017, pp. 15-25, doi: 10.1177/ 1468087416686699.

23. Rakopoulos, C.D., Kosmadakis, G.M., and Pariotis, E.G., Critical Evaluation of Current Heat Transfer Models Used in CFD In-Cylinder Engine Simulations and Establishment of a Comprehensive Wall-Function Formulation, Applied Energy, 87(5), May 2010, pp. 1612-1630, doi: 10.1016/j.apenergy. 2009.09.029.

24. Suzuki, T., Oguri, Y., and Yoshida, M., Heat Transfer in the Internal Combustion Engines, $S A E$ 2000 World Congress, Detroit (MI, USA), Mar. 2000, SAE Technical Paper 2000-01-0300, doi: 10.4271/2000-01-0300.

25. Ichiyanagi, M., Kojima, K., Joji, H., Matsui, H., and Suzuki, T., Development of On-Board In-Cylinder Gas Flow Model for Heat Loss Estimation of Diesel Engines, International Journal of Industrial Research and Applied Engineering (JIRAE), 3(2), Oct. 2018, pp. 69-77, doi: 10.9744/JIRAE.3.2.6978.

26. Sawamura, Y., Goto, D., Kojima, K., Matsui, H., Haoyu, C., Ichiyanagi, M., and Suzuki, T., Validation of On-Board In-Cylinder Gas Flow Model and Wall Heat Transfer Prediction Model Using PIV Measurement in CI Engine, 2018 JSAE Annual Congress Autumn, Nagoya (Japan), Oct. 2018.

27. Ichiyanagi, M., Matsui, H., Woo, J., Kumura, T., and Suzuki, T., Development of On-Board Model for Polytropic Index Prediction during Compression Stroke of CI Engine, Transactions of Society of Automotive Engineers of Japan, 49(2), 2018, pp. 168-174, doi: 10.11351/jsaeronbun.49.168.

28. Ichiyanagi, M., Joji, H., Matsui, H., Yilmaz, E., and Suzuki, T., Application of On-Board Polytropic Index Prediction Model for Compression Stroke of Diesel Engine to Transient Driving Conditions, Transactions of Society of Automotive Engineers of Japan, 49(5), 2018, pp. 938-943, doi: 10.11351/ jsaeronbun.49.938.

29. Dittus, F.W. and Boelter, L.M.K., Heat Transfer in Automobile Radiators of the Tubular Type, University of California Publications in Engineering, 2(13), University of California Press, 1930. 